Brit. Heart f., 1969, 31, 80.

\title{
Haemodynamic Effects of Nitroglycerin in Normal Subjects During Supine and Sitting Exercise
}

\author{
B. CHRISTENSSON, I. NORDENFELT, H. WESTLING, AND T. WHITE \\ From the Departments of Cardiology and Clinical Physiology, Lasarettet, Lund, Sweden
}

In a study on patients with coronary heart disease (Christensson, Karlefors, and Westling, 1965) it was found that one of the main effects of nitroglycerin during exercise was a reduction of the stroke volume and cardiac output. The investigation also indicated that the action of nitroglycerin was more pronounced in patients who exercised in the sitting than in the supine position. Decrease of the stroke volume and cardiac output was also shown in normal subjects during sitting exercise (Nordenfelt and Westling, 1967). The measurements of the cardiac output, in these two investigations, were performed when nitroglycerin had its maximal effect on the heart rate, i.e. about 4-7 minutes after the tablets were given. On the other hand, Hoeschen et al. (1966) reported that nitroglycerin caused an increase of the cardiac output during exercise both in normal subjects and in patients with coronary heart disease. The effect appeared 6 minutes after and was more marked 9 minutes after the drug was administered. During these experiments the subjects were seated in a chair (a position "between" seated and recumbent, (M. McGregor, 1967, personal communication). A similar effect of nitroglycerin, i.e. increased cardiac output, has also been found by Najmi et al. (1967) who exercised patients with coronary insufficiency in the supine position.

One possible explanation of the contradictory results mentioned might be that nitroglycerin during exercise causes an increase of the cardiac output after an initial decrease, and the measurements of the cardiac output might have been made at different times after giving the drug. It is also likely that the posture of the exercising subjects is of importance for the action of nitroglycerin. The present investigation therefore contains serial observations of the haemodynamic effects of nitroglycerin in normal subjects in the sitting and supine position up to 25 minutes after administration of the drug.

Received May 31, 1968.

\section{SUBJECTS AND METHODS}

Ten healthy male subjects were studied, two of them twice. They were 25 to 52 years old (mean 31 years).

The experiments were made in the morning after the subjects had had a light meal. Polyethylene catheters were introduced into one cubital vein and one brachial artery. The resting cardiac output was measured in the supine position in all subjects. Exercise tests on Elema's electrically-braked bicycle were made in either the sitting (i.e. the "natural" position for cycling) or in the supine position. The working intensity was in all cases $600 \mathrm{kpm}$. $/ \mathrm{min}$. The cardiac output was determined when the subjects had reached steady state as judged by the heart rate, i.e. after 6-8 minutes. A nitroglycerin tablet (Dumex, $0.5 \mathrm{mg}$.) was then given sublingually and new determinations of the cardiac output were made 4, $6,9,15$, and 25 minutes after the tablet had been dissolved, which took about half a minute. One of the subjects was examined twice in the sitting position. The first time he received nitroglycerin, and the second time, 2 months later, an inert pill. One subject was examined first in the sitting position and 4 months later in the supine position. The results of both examinations are included in the Table. Cardiac output was measured with the indicator dilution technique with bromsulphalein as indicator (Wassén, 1956). Arterial pressures were measured by inductance manometers and recorded on a direct-writing electrocardiograph (Elema 81). Mean arterial pressure was obtained by electrical integration. Heart rate was measured from a simultaneously recorded electrocardiogram.

\section{RESULTS}

From the Table and Fig. $1^{\star}$ it can be seen that after nitroglycerin there was a reduction of the stroke volume both in the supine and sitting position. In the supine position the decrease of the stroke volume was fully compensated for by the increased heart rate and thus there was no significant change of the cardiac output up to 25 minutes. During the sitting exercise, however, there was a significant fall $(p<0.05)$ of the cardiac output as
* The detailed results may be obtained from the authors. 
TABLE

HAEMODYNAMIC OBSERVATIONS DURING CONTINUOUS EXERCISE $(600 \mathrm{kpm}$. $/ \mathrm{min}$.) IN NORMAL SUBIECTS: MEAN VALUES BEFORE AND MEAN CHANGES UP TO 25 MINUTES AFTER NITROGLYCERIN (0.5 mg. SUBLINGUALLY) WAS GIVEN

\begin{tabular}{|c|c|c|c|c|c|c|c|c|c|c|c|c|}
\hline & \multicolumn{6}{|c|}{ Supine } & \multicolumn{6}{|c|}{ Sitting } \\
\hline & \multirow[t]{2}{*}{ Before } & \multicolumn{5}{|c|}{ After } & \multirow[t]{2}{*}{ Before } & \multicolumn{5}{|c|}{ After } \\
\hline & & $4 \mathrm{~min}$ & $6 \mathrm{~min}$. & $9 \mathrm{~min}$. & $15 \mathrm{~min}$. & $25 \mathrm{~min}$. & & $4 \mathrm{~min}$ & $6 \mathrm{~min}$ & $9 \mathrm{~min}$. & $15 \mathrm{~min}$. & $25 \mathrm{~min}$. \\
\hline $\begin{array}{l}\text { Heart rate } \\
\text { (beats/min.) }\end{array}$ & 113 & +15 & +15 & +12 & +12 & +15 & 123 & +12 & +12 & +10 & -3 & -3 \\
\hline $\begin{array}{l}\text { Cardiac output } \\
(1 . / \mathrm{min} .)\end{array}$ & $14 \cdot 7$ & $-0 \cdot 1$ & $+0 \cdot 7$ & -0.2 & +0.9 & +0.5 & $14 \cdot 4$ & $-1 \cdot 8$ & $-1 \cdot 7^{\star}$ & $-1 \cdot 4$ & -0.4 & \pm 0 \\
\hline $\begin{array}{l}\text { Stroke volume (ml.) } \\
\text { Arterial } \\
\begin{array}{l}\text { pressure } \\
\text { (mm. Hg) }\end{array}\left\{\begin{array}{l}\text { systolic } \\
\text { diastolic } \\
\text { mean }\end{array}\right. \\
\text { Number of subjects }\end{array}$ & $\begin{array}{r}132 \\
167 \\
80 \\
108 \\
5\end{array}$ & $\begin{array}{r}-14 \\
-12 \\
-1 \\
-8 \\
5\end{array}$ & $\begin{array}{r}-9 \\
-12 \\
-3 \\
-7 \\
5\end{array}$ & $\begin{array}{r}-11 \\
-12 \\
-4 \\
-6 \\
5\end{array}$ & $\begin{array}{r}-5 \\
-14 \\
-6 \\
-9 \\
5\end{array}$ & $\begin{array}{r}-11 \\
-16 \\
-8 \\
-10 \\
5\end{array}$ & $\begin{array}{r}118 \\
164 \\
78 \\
107 \\
6\end{array}$ & $\begin{array}{r}-23 \\
-21 \\
-3 \\
-7 \\
6\end{array}$ & $\begin{array}{l}-15^{\star} \\
-24 \\
-6 \\
-8 \\
6\end{array}$ & $\begin{array}{r}-18 \\
-17 \\
+1 \\
-4 \\
6\end{array}$ & $\begin{array}{r}-1 \\
-15 \\
-3 \\
-9 \\
4\end{array}$ & $\begin{array}{r}+3 \\
-14 \\
-3 \\
-7 \\
4\end{array}$ \\
\hline
\end{tabular}

$\star$ Only 4 subjects.

the stroke volume decreased more than the heart rate increased. The reduction of the cardiac output was most pronounced at the measurements in the 4th, 6th, and 9th minute; in the 15th minute the decrease had nearly vanished and had completely disappeared after 25 minutes. Fig. 2 shows the effect of nitroglycerin compared with that of placebo in the sitting position, and it is clear that in this subject there was no significant change of the cardiac output after placebo.

The systolic pressure was lowered by nitroglycerin more in the sitting than in the supine position. The mean and diastolic pressures were slightly reduced in both positions (Table).

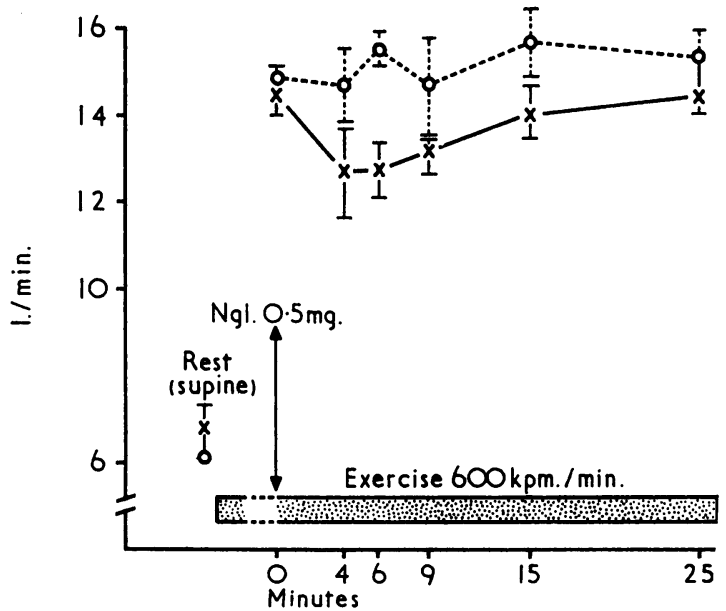

FIG. 1.-Mean values of cardiac output ( \pm S.E.M.) in normal subjects during continuous exercise $(600 \mathrm{kpm}$. $/ \mathrm{min}$.) in the sitting and supine positions before and after nitroglycerin $(0.5 \mathrm{mg}$. sublingually). The value at $0 \mathrm{~min}$. was recorded just before nitroglycerin was given. Numerical values of changes observed are given in the Table. Cardiac output during rest is also shown. $\mathrm{O}--\mathrm{O}$ supine, $\mathrm{X} \longrightarrow \mathrm{X}$ sitting.
Arterial pressures, and in the supine position also the heart rate and stroke volume, were not restored to the initial values 25 minutes after nitroglycerin had been given. This might not necessarily be an effect of nitroglycerin, as it is known that during prolonged exercise there is a gradual increase of the heart rate, a corresponding reduction of the stroke volume, and fall of arterial pressures (Ekelund, 1967).

\section{COMMENTS}

It is evident from the present study that the posture of the exercising subject is of importance for the effect of nitroglycerin, as was suggested by

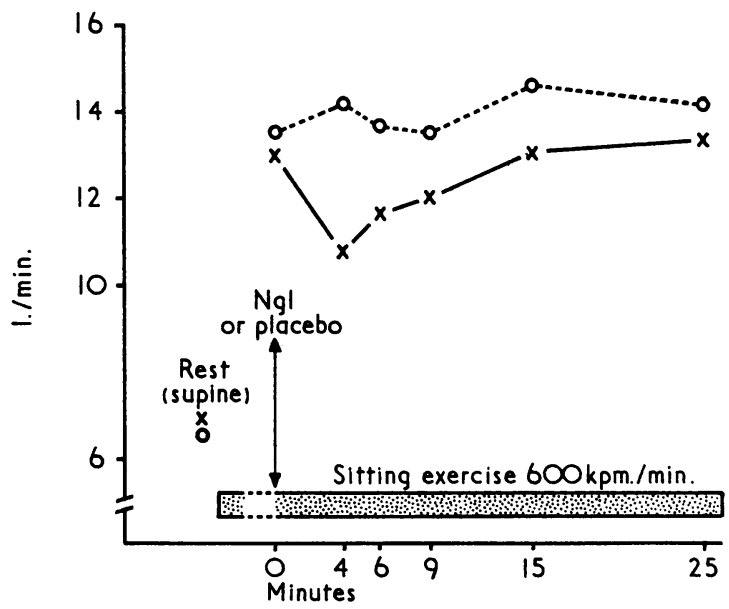

Fig. 2.-Cardiac output in one normal subject during sitting exercise $(600 \mathrm{kpm}$. $/ \mathrm{min}$.) before and after nitroglycerin or placebo. The value at $0 \mathrm{~min}$. was recorded just before nitroglycerin or placebo was given. Cardiac output during rest is also shown. $\mathrm{O}--\mathrm{O}$ placebo, $\mathrm{X} \longrightarrow \mathrm{X}$ nitroglycerin. 
Christensson et al. (1965). This is quite reasonable as one of the main actions of nitroglycerin and related drugs seems to be relaxation of the capacitance vessels (Weiss, Wilkins, and Haynes, 1937; Wilkins, Haynes, and Weiss, 1937; Åblad, 1963), which causes pooling of the blood in the lower part of the body and diminished filling of the heart. Such pooling of the blood is of course more pronounced when the subject is sitting than when supine, and can be regarded as the logical explanation of the lowered cardiac output caused by nitroglycerin in the sitting position.

The posture of the subjects during the experiments might thus partly explain the discrepancy between the findings mentioned earlier (Hoeschen et al., 1966; Najmi et al., 1967) and the results from this laboratory. There was, however, in this study no significant increase of the cardiac output in the supine position as long as 25 minutes after giving nitroglycerin, while the above-mentioned authors reported an increased cardiac output. The reason for this discrepancy is unknown. However, it should be pointed out that the dye dilution techniques for the measurement of cardiac output used by Hoeschen et al. (1966) and by Najmi et al. (1967) were slightly different from that used in the present investigation. Further, only normal subjects were studied by us.

\section{SUMMARY}

The haemodynamic effects of nitroglycerin were studied in normal male subjects during supine and sitting exercise. Cardiac output was measured repeatedly up to 25 minutes after nitroglycerin was given. In the supine position there was no significant change of the cardiac output, while in the sitting position the cardiac output decreased significantly.

The importance of the posture of the exercising subject for the action of nitroglycerin is discussed.

Support from the Swedish National Association against Heart and Lung Diseases is gratefully acknowledged.

\section{REFERENCES}

Åblad, B. (1963). A study of the mechanism of the hemodynamic effects of hydralazine in man. Acta pharmacol. (Kbh.), 20, Suppl. 1.

Christensson, B., Karlefors, T., and Westling, H. (1965) Haemodynamic effects of nitroglycerin in patients with coronary heart disease. Brit. Heart $\mathcal{F}$., 27, 511.

Ekelund, L.-G. (1967). Circulatory and respiratory adaption during prolonged exercise. Acta physiol. scand., 70, Suppl. 292.

Hoeschen, R. J., Bousvaros, G. A., Klassen, G. A., Fam, W. M., and McGregor, M. (1966). Haemodynamic effects of angina pectoris, and of nitroglycerin in normal and anginal subjects. Brit. Heart f., 28, 221.

Najmi, M., Griggs, D. M., Jr., Kasparian, H., and Novack, P. (1967). Effects of nitroglycerin on hemodynamics during rest and exercise in patients with coronary insufficiency. Circulation, 35, 46.

Nordenfelt, I., and Westling, H. (1967). A note on the haemodynamic effects of nitroglycerine and related substances in normal subjects. Acta med. scand., Suppl. 472 , p. 81.

Wassén, A. (1956). The use of bromsulphalein for determination of the cardiac output. Scand. F. clin. Lab. Invest., 8, 189.

Weiss, S., Wilkins, R. W., and Haynes, F. W. (1937). The nature of circulatory collapse induced by sodium nitrite. f. clin. Invest., 16, 73.

Wilkins, R. W., Haynes, F. W., and Weiss, S. (1937). The role of the venous system in circulatory collapse induced by sodium nitrite. f. clin. Invest., 16, 85. 